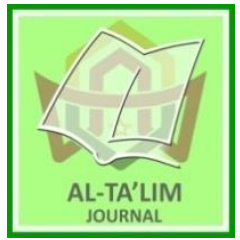

AL-TA'LIM JOURNAL, 28 (1), 2021, (9-25)

(Print ISSN 1410-7546 Online ISSN 2355-7893)

Available online at http://journal.tarbiyahiainib.ac.id/index.php/attalim

\title{
Explored Jordanian Math Teacher's Practices, and Belief Change in Implementing Mobile Applications in Education
}

Received: 04 ${ }^{\text {th }}$ December 2020 Revised: 06 ${ }^{\text {th }}$ February 2021; Accepted: $28^{\text {th }}$ February 2021

Permalink/DOI: http://dx.doi.org/10.15548/it.v28i1.672

\author{
Khaled Ahmed Aqeel Alzubi \\ The Hashemite University, \\ Zarqa,13133, Jordan \\ E-mail: khaledaa@hu.edu.jo
}

\begin{abstract}
The aim of This study explored Jordanian math teachers' beliefs, practices, and belief change in implementing mobile applications in education Learning mathematics is a major focus of educational institutions at all levels and technology has long been an important teaching tool in the field of mathematics. Multiple sources of qualitative data were generated including metaphors, lesson plans and interviews with 17 math teachers. Although teachers considered Implementing mobile applications in education as an effective method that benefit student learning and they demonstrated progress in changing their beliefs moving from subject to didactic dimension through Implementing mobile applications in education, their practices remained partially aligned with their perceived belief changes. This discrepancy could be attributed to several encountered challenges, including teachers' lack of confidence, difficulty in facilitating student collaboration, structural constraints, additional workload, and the lack of school and peer support. Results suggest the need for different types of "problems" and approaches such as more direct instruction, and higher feasibility in teachers' autonomy when Implementing mobile applications in education. Outcome of this study has a few implications. First, discrepancy between belief and practice of implementing mobile applications. identified in this study suggests that appropriate and sufficient professional development activities are needed. The MOE and schools in Jordan should further articulate policy goals and standards that facilitate student-centered approaches for teachers. System and institutional supports such as reducing teachers' workload, providing sufficient time for students' activities during implementing mobile applications. sessions and for teachers' collaboration, and involving both students and teachers in defining.
\end{abstract}

Keywords: Math teacher's beliefs; teacher's practices; belief change; implementing mobile applications in education.

How to Cite: Alzubi, K. (2021). Explored Jordanian Math Teacher's Practices, and Belief Change in implementing mobile applications in education. Al-Ta lim Journal, 28(1). doi:https://doi.org/10.15548/jt.v28i1.672

\section{INTRODUCTION}

Most of the current generation in the schools and universities cannot see the world without mobile technology. Mobile devices are a part of the daily life of the students inside and outside the classroom. Other techniques such as the paper and pencil and the computer programs are also acceptable. (Dias \& Victor, 2017; Grant et al., 2015).

The results, also, showed that the mobile devices were a viable alternative of the desktop computers for helping in 
conceptualizing an understanding the math concepts. Meanwhile, the mobile devices were used to promote the collaborative learning environments, which indicated the mobile devices' abilities to narrow the gap between the school math and the world; as compared with the schoolbooks. Consequently, an interactional math model of the applications of the mobile learning, which are run by Apple or Android systems by using the web services, can facilitate realistic learning everywhere (Galligan et al., 2010; Thomas \& Muñoz, 2016).

These studies reported the challenges encountered such as embracing constructivist beliefs and lacking an understanding in implementing mobile applications in education (Lee et al., 2014) as all as a willingness to share the authority of content knowledge with students (Savin-Baden, 2003b, 2003a). There is a need for additional knowledge about Implementing mobile applications in education and its effectiveness on student learning. However, it is useful to understand how teachers experience the process of changing their roles, their practices of implementation and how they perceive the changes needed. Therefore, this study aimed to fill the literature gap of teachers' belief of their roles and perceptions of their belief change in implementing mobile applications in education.

\section{Although the effectiveness of implementing mobile applications in educations well-researched, there is limited research concerning Implementing mobile applications in education in Jordan. This study contributes to this limitation by presenting findings those Jordanian math teachers schools consider implementing mobile applications in educations an effective method-benefiting student learning.}

Teachers demonstrated progress in changing their beliefs moving from the subject to the didactic dimension through implementing mobile applications in education. Nevertheless, their practices remained partially aligned with their perceived belief changes. This discrepancy could be attributed to the encountered challenges when implementing mobile applications in education. including teachers' insecurity and lack of confidence, difficulty in facilitating student collaboration, structural constraints and additional workload, and lack of peer and school support. This study suggests that teachers could be more influenced by the institutional constraints such as fulfilling curriculum standards and the consequences of potential failure.

Nevertheless, implementing mobile applications in education has feasibility in primary math education. However, scaffolding and direct instruction could be necessary at the early stages of education. Also, there is a need for different types of problems and approaches when applying Implementing mobile applications in education for secondary grades. There is a need for additional knowledge about Implementing mobile applications in education and its effectiveness on student learning. However, it is useful to understand how teachers experience the process of changing their roles, their practices of implementation and how they perceive the changes needed. Therefore, this study aimed to fill the literature gap of teachers' belief of their roles and perceptions of their belief change in implementing mobile applications in education.

The results showed that the mobile devices were a viable alternative of the desktop computers for helping in conceptualizing and understanding the math concepts. Meanwhile, the mobile devices were used to promote the collaborative learning environments, which indicated the mobile devices' abilities to narrow the gap between the school math and the world; as compared with the schoolbooks. Consequently, an interactional math model of the applications of the mobile learning, which are run by Apple or Android systems by using the web services, can facilitate realistic learning everywhere (Galligan, Loch, McDonalr \& Tayler, 2010; Thomas \& Muñoz, 2016). 
Many educators believe that the mobile devices are among the best educational vehicles in teaching mathematics because they have various instruments and techniques to perform an effective role in teaching vital and realistic mathematics, renewing methods of teaching and applying the different educational strategies. They, further, help in attracting the students' attention, applying modern teaching vision, providing prompt feedback to the students and contributing in giving realistic solutions for the educational problems they face (Hohenwarter \& Lavicza, 2007; Kebritchi et al., 2010; Li \& Ma, 2010; Zhao et al., 2010)

Therefore, we find that the math teaching-learning approach is closely and strongly tied to the modern technology particularly in the mobile devices. Technology provides dynamic software instruments that are directed to math teaching-learning within contexts that enable students understand math in a meaningful manner. As a result, the educational Applications in the mobile devices enable the students to interact with these devices to a wide extent, link the information and represent them in different types and shapes (Abramovich, 2013; Chaamwe, 2010; Hollerbrands, 2007).

The mobile devices with their modern applications contributed in providing interactive and dynamic educational environment, which enabled the students to implement the exercises, problems and tasks, and develop the students' abilities to maximize the use of such modern techniques in their learning. (Baki et al., 2011), and (Gürsul \& Keser, 2009) see that such mobile devices applications saved the efforts spent to make the student acquires basic learning skills in comparison with the conventional methods currently applied in math teaching

Beliefs can be defined as "mental constructs that represent the codifications of people's experiences and understandings" (Törner, 2002). Beliefs are often related to practice, and in particular, teachers' beliefs have a strong effect and influence that shapes teachers' practice of applying strategies and organizing teaching activities (Burridge \& Carpenter, 2013; Mihaela \& Alina-Oana, 2015; Schoenfeld, 2016). Previous studies suggest a positive relation between teachers' beliefs and their role, classroom practice, instructional decision, the relationships they build with students and their work environment (Pajares, 2003). Teachers' beliefs regarding their roles are essential in their profession because they reflect their understanding of teaching and impacts lesson plans, classroom instruction and interactions with students (Ahonen et al., 2014). In addition, teachers' cultural backgrounds, individual experiences and contextual factors all contribute to the teachers' beliefs in their roles (Wang \& Du, 2016). Teachers who hold a strong belief in a teaching approach achieved a higher level of implementation (Burridge \& Carpenter, 2013). Implementing innovations and changes from outside without addressing the concerns of the teacher under the circumstances in which they work could lead to the failure (Korthagen, 2010).

Individuals' beliefs are continually undergoing changes when faced with new perceptions from the environment that challenge assumptions and when they compare, contrast and evaluate new experiences with prior experiences and perceptions. Belief change starts when teachers reflect, which produce in turn nuances and changes of behavior over time (Mihaela \& Alina-Oana, 2015). Teachers who are changing from a teacher-centered approach to a student-centered approach make choices based on the new beliefs and assumptions. For example, they reduce the time for lecturing and change their teaching role from information transmitter to learning facilitator (Fullan, 2014). This change process can be time costly and difficult for teachers to accept and adopt, therefore teachers must be supported by appropriate professional development activities (Al Said et al., 2019; Savin-Baden, 2003b)

Due to the vital importance of mobile applications in education, the National Council of Teachers of Mathematics (NCTM, 2000) called for building educational policies that utilize technology in math teaching 
through the use of the smart devices and their different applications. Thereby, students receive teaching programs in mathematics to a wide extent, due to the ability of technology to promote the students' learning through the embodiment of the math ideas in visible shapes. They, also, facilitate data organization, storing, analysis and retrieval in different ways, and apply the arithmetic operations with accuracy and efficiency. Therefore, NCTM (2000) adopted technology within the principles upon which the school math is based.

Because of the multiple programming languages, differences of their levels, and existence of specialized companies in education and qualified cadres in the mobile devices and mathematical areas, there are large numbers of different educational applications that cover all the math aspects. Still, there are specialized Applications in specific domains branches of mathematics. Such Applications compete in providing effective programming tools that teach specific subjects. For instance, there are Applications specialized in graphics, others in geometry, and so on, which are suitable for the different age groups (Korenova, 2012; Li, 2007)

Sketchpad Application is one of the important Application in math teaching, which was introduced for the first time in the United States of America in 1991 by its designer, Nicholas Ackee. It was based on the idea that the use of computer in education is a must so the program was developed as part of the Visual Geometry Project, when its designer joined the project and added a meaningful development to the program, until he approached its initial version. Sketchpad is also the most important interactional geometry program, which fosters building all the 2D (two dimensional) formats, where the user can move and activate the figures and formats to discover their characteristics. The Application provides the user an advanced calculator to carry out the arithmetic operations, draw all the conjunctions and find their equations (Leong, 2013).

\section{METHODS}

Thirty Jordanian math teachers were invited to by emails participate in this study. Among them 17 teachers responded to the metaphor survey and 15 teachers provided their lesson plans before and after they implemented mobile applications in education. Eight teachers participated in the interviews by mobile. As can be seen in the following table

Table 1. Teachers Information

\begin{tabular}{|c|c|c|c|c|c|c|c|}
\hline Teacher & Gender & age & Teaching & Education & metaphors & Lesson & interviewer \\
\hline & & & experience & grade & & plan & \\
\hline $\mathrm{T} 1$ & male & 31 & 6 & b.d.in math & $\checkmark$ & $\checkmark$ & \\
\hline $\mathrm{T} 2$ & male & 34 & 9 & b.d.in math & $\checkmark$ & $\checkmark$ & $\checkmark$ \\
\hline T3 & male & 37 & 11 & b.d.in math & $\checkmark$ & $\checkmark$ & $\checkmark$ \\
\hline T4 & male & 46 & 20 & b.d.in math & $\checkmark$ & $\checkmark$ & $x$ \\
\hline T5 & male & 30 & 5 & b.d.in math & $\checkmark$ & $\checkmark$ & $\checkmark$ \\
\hline T6 & male & 37 & 13 & b.d.in math & $\checkmark$ & $\checkmark$ & $\checkmark$ \\
\hline $\mathrm{T} 7$ & male & 34 & 11 & b.d.in math & $\checkmark$ & $\checkmark$ & $\checkmark$ \\
\hline T8 & male & 33 & 8 & b.d.in math & $\checkmark$ & $\checkmark$ & $x$ \\
\hline T9 & male & 29 & 6 & b.d.in math & $\checkmark$ & $\checkmark$ & $x$ \\
\hline T10 & male & 34 & 7 & b.d.in math & $\checkmark$ & $\checkmark$ & $\checkmark$ \\
\hline T11 & male & 31 & 6 & b.d.in math & $\checkmark$ & $\checkmark$ & $\checkmark$ \\
\hline T12 & male & 28 & 6 & b.d.in math & $\checkmark$ & $\checkmark$ & $\checkmark$ \\
\hline T13 & male & 31 & & b.d.in math & $\checkmark$ & $\checkmark$ & $x$ \\
\hline T14 & male & 37 & & b.d.in math & $\checkmark$ & $\checkmark$ & $x$ \\
\hline T15 & male & 36 & & b.d.in math & $\checkmark$ & $\checkmark$ & $x$ \\
\hline T16 & male & 37 & & b.d.in math & $\checkmark$ & $\checkmark$ & $x$ \\
\hline T17 & male & 36 & & b.d.in math & $\checkmark$ & $\checkmark$ & $x$ \\
\hline
\end{tabular}

All participants were male teachers and Native Arabic speakers they holding bachelor's degrees in mathematics. The participants' teaching experience ranged between 4-24 years, among them 16 had more than eight years' teaching experiences. The 
letter " $\mathrm{T}$ " was used for coding teachers as participants volunteering preferred anonymity in the study.

\section{Research Design and Data Generation}

A qualitative research was designed because it uncovers "identities, experiences, beliefs and orientations" (Talmy, 2010). Multiple sources of data were generated including metaphor, lesson plan, and interviews. There were three phases of data generation in this study, metaphors, lesson plans and participant interviews.

Metaphors are used to transfer the features of one thing to another by considering the similarities between these two things (Lakoff \& Johnson, 2008). Teachers' metaphors can be used as an indirect way to understand teachers' beliefs concerning teaching, learning and their role, which may be implicit or hidden (Löfström \& PoomValickis, 2013). To explore teachers' beliefs, in phase one of the study "metaphors," participants were asked to provide metaphors through a survey. For example, the survey requested participants to provide two metaphors delivering a brief clarification of their metaphor by completing the statement, "Being a teacher is like...because...". The first was to describe the teacher's role prior to Implementing mobile applications in education and the second was to describe the teacher's role after implementing mobile applications in education.

A lesson plan, in the form of a combination guide, resource, and historical document, is a useful tool that reflects teaching philosophy, student population, textbooks, and goals for students (Jensen, 2001). Teachers holding a constructivist belief design instructional activity that focus on students as active participants and emphasizes facilitating student inquiry (Laius et al., 2009). To explore how teachers practice Implementing mobile applications in education., in phase two of the study 'lesson plans," participant teachers' lesson plans including prior to the Implementing mobile applications in education. and after Implementing mobile applications in education. how their beliefs framed their teaching practices.

Interviews are useful tools to capture teachers' thinking, and beliefs through the conversations than other data collection tools (Patton, 2014). In phase three of the study "participant interviews,", participant teachers were interviewed to gain a deeper understanding of their beliefs, experiences, opinions and feelings (Brinkmann \& Kvale, 2005; Kvale \& Brinkmann, 2009). The comparison between metaphor results and lesson plans analysis brought insights for the development of interview questions, which were focused on their experiences, perceptions of implementing mobile applications, belief changes, and current practices and challenges. All eight interviews took place in the teachers' schools each lasting 15-30 minutes. The interviews were conducted in Arabic and audio recorded, transcribed and translate

\section{Data Analysis}

An integrated approach was employed for data analysis comparing multiple sources of qualitative data, combining both a thematic approach (Kvale \& Brinkmann, 2009) and theory driven approach (Namey et al., 2008). For the metaphor analysis, a theory-driven deductive content analysis was applied using the categorization created by (Löfström \& Poom-Valickis, 2013). The lesson plans were first analyzed following the eight-step guidelines of the Implementing mobile applications in education teaching design framework before patterns were summarized. Interview transcripts were analyzed with emerging themes and comparing to literature (Du, 2012; Du et al., 2013; Du \& Chaaban, 2020).

\section{RESULT AND DISCUSSION}

The following section introduces findings from participants' developed metaphors, an analysis of the Implementing mobile applications lesson plans and responses from interviews. These findings are presented by addressing each research 
question individually followed by a discussion.

\section{How do Math Teachers Perceive the Implementing mobile applications as a Useful Method?}

All of the eight interviewed teachers found implementing mobile applications useful to improve students' mathematics problem-solving and deep learning levels. Six of them (T5, T6, T8, T11, T13, T16) mentioned that Implementing mobile applications requires critical thinking and analytical skills. Moreover, two teachers (T4 and T10) mentioned that students gained deeper understanding through reading questions and relating to the problem inquiry process. As one teacher stated, "This method gives more space for thinking and analyzing mathematical problems. It gives them a chance to think deeply and critically to solve different math problems." (T10).

In addition, interviewed teachers reported their observation of improved students' independence in learning witnessing students taking more responsibility for their own learning. Four teachers (T4, T6, T10, T11) mentioned that their students become more independent in using their knowledge and skills to solve problems. Five teachers (T5, T8, T10, T13, T16) identified improved academic performance from their students. All eight teachers believed that not only high achievement, but also low achievement students demonstrated their ability to work independently in a Implementing mobile applications process. In particular, for the low achievement students, the Implementing mobile applications process helped them gain confidence to engage in the inquiry process, even low achieving students find a solving strategy that suits their abilities...sometimes they understand the explanation from peer students better" (T13).

\section{Motivation and engagement}

Motivation is one of the most important drivers to learn mathematics, otherwise it could become boring and over abstract. Low learning motivation in education in Jordan has been reported as a critical issue. All eight teachers who were interviewed indicated there is a low learning motivation among students. All eight teachers believed that the Implementing mobile applications method was highly useful in this matter and reported students' increased motivation and engagement to learning as a visible improvement in the Implementing mobile applications environment. In particular, four teachers mentioned how Implementing mobile applications in education. motivated and encouraged low achieving students. For example, one teacher (T5) stated, "I had some weak students they all gained more motivation, it made them more willing to solve additional problems to try their new skills out". (T5).

\section{Collaborative learning}

Students' development in functioning and communicating in a group setting was also highlighted as a major benefit from implementing mobile applications in this study. These teachers explained their experience with collaboration in two aspects. First, there were three teachers (T6, T10, T11) who discussed "student-teacher" collaboration, reflecting a change in the teacher and students' role where teachers reduced their control of dominance over the class and students began to move away from being passive receivers of knowledge. For example, one of the three teachers ( $\mathrm{T}$ 11) stated, "We both work together. I no longer give out rules for them to memorize and use. We are all looking for solutions." (T11).

Five teachers addressed "studentstudent" collaboration (T4, T5, T8, T10, T13, T16). Their students felt responsible for helping each other and accepted their peers' opinions. One teacher stated, "My students' behavior changed. They are listening to each other and are trying different suggestions from their peers. They like to share ideas and solutions." (T8).

\section{Addressing individual differences}

One of the major challenges for teachers in the government schools is the 
students' different perspectives and methods of approaching mathematical problems that reflect their different abilities, background, and environment. Teachers suggested that through the Implementing mobile applications, every student can choose a solving strategy he or she understands. Through the Implementing mobile applications, every student has space to work on a problem that is suitable to their own speed and preference and find strategies that work for each individual. In particular, two participants mentioned how team work provide support from not only from teachers but also from others students and this proved helpful to low achieving students. One teacher mentioned, "This generation is different. They need different strategies to match their learning styles.

\section{How do the Math Teachers Practice Implementing Mobile Applications?}

Data analysis from teachers' interviews and lesson plans provided an overview of how they implemented implementing mobile applications. The 17 teachers' lesson plans were analyzed respectively by pre- Implementing mobile applications and current practice, following the eight steps of the guideline of implementing mobile applications teaching design proposed by Du (2012).

Lesson plan samples prior to Implementing mobile applications were found to be nearly identical, despite school differences. This could be due to the fact that all schools must follow the MOE requests and both the guidelines of the textbook and the teacher's book. Comparing lesson plan the data analysis results with interview transcripts, two general patterns of implementing mobile applications practices were summarized, mainly by frequency counting of addressing each step of the procedure. The two patterns are described as below.

First, in four of the eight suggested steps, all collected lesson plans (except T2 and T10 missing prior Implementing mobile applications examples) included steps 1, 3, 4, and 8 in both prior and post Implementing mobile applications. Nevertheless, differences of priorities and focuses were observed between prior and post implementing mobile applications lesson plans in these aspects.

Regarding step 1, all lesson plans prior to Implementing mobile applications addressed the context, focusing on classroom environment and physical facilities. While in the Implementing mobile applications lesson plans, all teachers elaborated the strategies of choosing specific mathematics problems considering their connection to the social contexts that would make sense to Arabic students. For example, one teacher utilized the topic of camel racing, asking students to calculate the speed of camels when given the distance and time using locations in Jordan.

Concerning steps three "Designing Teaching Activity" and four "Encouraging Teamwork," the prior to Implementing mobile applications lesson plans structured class activities following the MOEHE request and teacher book guidelines. No variation was expected and observed in the samples. Implementing mobile applications lesson plans identified a range of activities. Three teachers (T1, T4, and T5) included problemsolving strategies, involved higher thinking questions with no model answers, and expected students to work independently. Students then shared solutions with their team and presented a few options from team-based results to discuss with teacher. The teacher would analyze various options for the solutions with the team. A significant amount of time is planned for student-student interaction in team. 12 among the 17 teachers (T3, T6, T7, T8, T10, T11, T12, T13, T14, $\mathrm{T} 15, \mathrm{~T} 16, \quad \& \mathrm{~T} 17)$ designed their Implementing mobile applications activities combining students working independently and discussing with peers, before the teachers with a model answer at the end provided instruction. Two teachers (T2 and T9) used textbook questions with neither supporting activities, nor higher thinking questions and team work.

Evaluation forms, as part of the lesson plan documents, were highly emphasized in 
both prior and after lesson plans by all the 17 teachers, because these are required by the MOE, as they explained. The evaluation forms, prior to implementing mobile applications were mainly focused on evaluating whether the textbook objectives were addressed or not. The lesson plans for Implementing mobile applications specified questions about students' abilities and how the group was conducted in addition, evidence from the students' daily work was collected and reported on a form titled classroom record, including their reactions, achievements and feedback in the problemsolving process.

Second, the other four of the eight proposed steps - Step 2 "Defining and communicating learning goals and outcome", 5 "Considering Learners' role," 6 "Considering Teachers' Role," and 7 "Assessment" - were not addressed in the lesson plans prior to Implementing mobile applications but were given attention at various levels in the Implementing mobile applications lesson plans. This is mainly because they were not required, and assessment was defined by MOE as following the required textbooks.

Assorted ways were observed in the Implementing mobile applications lesson plans. Four teachers (T1, T3, T4 and T5) planned to invite students to define the goals through classroom discussion with the support of the teacher. Two teachers (T10 and T16) defined the goals in the lesson plans and structured time to communication these goals with students. Eleven teachers (T2, T6, T7, T8, T9, T10, T11, T12, T13, T14, T15, and T17) defined the learning goals but did not plan time and activities to communicate the goals with their students. The reasons provided during interviews included limited class time, large class size and pressure to finish the requested schedule.

Six teachers (T1, T3, T4, T5, T16, and T17) stated in their lesson plans that students should play the main role in class with no direction from the teacher. Students should provide various solutions to Implementing mobile applications problems. In addition, teachers should play the role of evaluator and supporter only when help is needed. There were nine teachers (T6, T7, T8, T10, T11, $\mathrm{T} 12, \mathrm{~T} 13, \mathrm{~T} 14$, and $\mathrm{T} 15)$ that described the expected roles through the activity design, mentioning the plan of encouraging the students to question one another, clarify, compare and discuss before teacher modeling the correct solving strategy. However, they did not clearly define the roles of the teacher and students in implementing mobile applications lesson plans. During interviews, teachers reported that this plan could only be partially implemented because students.

Needed more guidance than expected. Two teachers (T2 and T 9) did not address the roles of teachers and students in their Implementing mobile applications lesson plan explaining in the interview that students should be directed by the teacher from the beginning of the exercise and should be provided with model answers.

Concerning Step 8 "assessment," five Implementing mobile applications lesson plans (T1, T3, T4, T5, and T16) included plans to communicate with students regarding how they would be assessed. The plans even encouraged students to identify what they already knew and what they needed to learn in order to solve the main problem. Other teachers did not show any considerations regarding involving students in the assessment

\section{How do the Math Teachers Perceive their Teaching Roles after Three Years' Implementing mobile applications? have they Experienced any Changes in their Perceptions?}

Based on previous work, Löfström, Poom-Valickis, and Hannula (2011) summarized six metaphors of teacher identity. They are: 1). The teacher as a subject matter expert who possesses deep knowledge and acts as knowledge transmitters to the learners; $2)$. The teacher as a didactic expert who facilitates students' understanding and who is trained in the teaching and learning process; $3)$. The teacher as a pedagogical expert who nurtures student values and morals; 4). The teacher as a self-referential metaphor that 
refers to the teacher's characteristics without considering his or her role as a teacher; 5). The teacher as a contextual metaphor referring to the characteristics of his or her work environment; 6). The teacher as a hybrid including elements of more than one of the above categories. Metaphors collected from the 17 teachers were analyzed based on these six categories as illustrated in Table 1. Researchers in this study individually coded addressed in after Implementing mobile applications survey (except for subject matter and contextual experts). There was a noticeable shift in teachers' metaphors from the subject to didactical role after implementing mobile applications (from 9 to 0 for subject experts and 2 to 12 for didactical experts). Prior to implementing mobile applications, subject expert was the most frequent metaphor prior Implementing mobile applications several teachers mentioned this stating, "The teacher is like a machine because they always work and plan for teaching, provide their students with knowledge in all circumstances without getting tired." (T10), "The teacher is like a prompter because they are at the core of learning process, and the source of information for students." (T4). After implementing mobile applications, there were no teachers who addressed this category.

After three years of implementing mobile applications implementation, didactics expert was the most commonly used metaphor. The number increased from two prior to Implementing mobile applications to twelve metaphors after Implementing mobile applications. Teachers mostly described math teachers as facilitators who help their students to learn and understand mathematics and enable the discovery of the new mathematical concepts. They also emphasize a more constructivist view of teaching and learning as well as the students' active role in the learning process. For instance, one of the teachers emphasized the importance of facilitating students' learning by guiding them to discover and understand mathematics described math teachers as a compass. The following comments demonstrate this shift in teachers' thinking. and categorized the metaphors then compared results. If their results varied, the metaphors were re-examined until the researchers agreed on the appropriate categorization.

As Table 1 illustrated, four of the six metaphors (except self-referential and contextual experts) categories were addressed in the prior implementing mobile applications survey, and four metaphor categories were

"The teacher is like a lighthouse: They guide the students to reach learning goals and lightning for them the path for reaching the learning goals. The teacher is like a compass. They help the students to find their direction. They listen to their students. The students are the heart of the learning process" (T6).

"The teacher is like an electricity generator: They help students carry on their way on bringing light to new information" (T12). The teacher is like the gear of a machine. Teachers are flexible; they build their expectations according to the students' levels, giving students the chance to say what they think and to conclude new information from their previous knowledge. They facilitate higher thinking skills in analyzing and evaluating their work"(T6).

In addition, three teachers provided a description of the pedagogical expert for both phases. They emphasized caring and kindness as a teacher's main role. For example, one teacher stated, "The teacher is like a tree: $\mathrm{He}$ give shade to others, provide students with the fruits of knowledge and treat them all with kindness." (T7)

There were minor changes that occurred in the self-referential and hybrid groups. No metaphors were represented in the category of self-referential expert prior implementing mobile applications and one teacher used it after implementing mobile applications stating, "The teacher is like the whole system. They do everything. They teach, raise, heal, provide basis, build and explain." (T13). Finally, two teachers used hybrid metaphors prior to Implementing mobile applications and one teacher after implementing mobile applications. "The teacher is like a blender: They blend between 
instructing, dictating, and knowledge providing. They have a great role in the learning process" (T6).

\section{The Challenges in Implementing mobile applications as Perceived by Teachers}

\begin{abstract}
Interview analysis identified a list of challenges perceived by the teachers regarding the implementing mobile applications. These were categorized into the four following themes; the lack of security and self-confidence; the difficulty in facilitating student collaboration, the lack of teacher collaboration and the extra workload created by the demand to achieve the regular curriculum standards.
\end{abstract}

First, the lack of security and selfconfidence. All interviewed teachers mentioned their nervous feelings during the implementation process. They indicated worrying about whether students would accept the new approach or not and how it would affect the classroom. Five teachers explained that this concern was because they had no prior experiences and worried whether any mistake or failure would put their jobs at risk.

Second, teachers expressed some difficulty in facilitating student collaboration. Although all teachers mentioned the benefits of collaboration in learning mathematics, facilitating the students to work together remained a challenge for all teachers. More specifically, four teachers explained that one of the reasons could be because of the students' diverse cultural backgrounds that made it difficult to collaborate. For example, one teacher (T16) stated, "they think differently because of their backgrounds are different, it takes time for them to explain to each other." There were five teachers that believed the lack of prior experiences with collaboration was a challenge for students. Three teachers pointed to the age of the students and the Jordanian culture as the reasons, as one explained "It is challenging with young girls to talk in front of their peers. The girls in this country are too shy." (T3).
Third, lack of teacher collaboration. Although teachers were encouraged to develop collaborative lesson plans, and they individually wished to share experiences and gain support from other teachers. All teachers reported that they found it hard to collaborate. One reason was there was lack of time and opportunities to communicate with each other and share experiences within school work hours. Another reason was peer teacher resistance. Half of the teachers mentioned that some their peer teachers did not accept the change strategy and participated in the implementing mobile applications only because of the top-down decision. Those who were resistant did not believe in the benefits of the implementing mobile applications and expressed negative attitudes, which made the daily practice difficult for those who held positive attitudes, as one teacher stated, "Not all teachers accepted this method because it is quite new to them. When some do not accept the implementing mobile applications, it makes it more challenging for us" (T4). Hence, they often felt "alone and lonely" within each school.

Fourth, all interviewed teachers explained that they had to achieve the regular curriculum standards and this created an extra workload. They considered this the main challenge the implementing mobile applications. As one said, "The quantity of curriculum standard to be covered is the biggest obstacle that my students and I face." (T8). This challenge also included the number of required questions to be covered from the students' book in each class and the model answer it presented for students to follow. As a teacher explained, "The students' book is too crowded with information and the questions are hard to fit in tight timeframes." (T11). Succeeding this issue was time limitations. All teachers reported that limited time was provided for preparation and delivery of the implementing mobile applications process. They indicated that students needed time to develop skills for the implementing mobile applications and also needed sufficient time to discuss the mathematical problems in the class. Also, teachers need time to prepare for lesson plans 
and develop new materials for the implementing mobile applications. Teachers felt they could not meet the required standards because of the time needed to solve and discuss the problem when using the implementing mobile applications approach. For example, one mentioned "We realized that the implementing mobile applications is time consuming. You know how hard it is for the teacher to control a large number of students in class. We also feel pressured with the workload" (T4).

Concerning how teachers perceive implementing mobile applications., teacher participants expressed four themes of benefits that held significant value for learners. Among these themes, three aligned with previous studies addressing implementing mobile applications. advantages perceived by K12 teachers concerning improving mathematical learning skills such as problem solving, critical and high-level thinking, motivation and engagement (Dole et al., 2017; Grant et al., 2015; Sungur \& Tekkaya, 2006; Tamim \& Grant, 2013). These results also demonstrated that implementing mobile applications. allowed teachers to take advantage of the power of social interaction to achieve learning goals (Dole, Bloom, \& Doss, 2017; Tamim \& Grant, 2013). These perceptions echoed university teachers' experiences of implementing mobile applications (Kazemi \& Ghoraishi, 2012; Lee et al., 2014). Previous studies on implementing mobile applications. in higher education reported university teachers' resistance to the belief that implementing mobile applications. would benefit student learning in subject knowledge, in particular regarding science fundamental contents (Moesby, 2004; Zhou et al., 2012). In comparison, the primary math teachers demonstrated more positive perceptions and attitudes towards the implementing mobile applications. impact on student learning in mathematical content knowledge. An additional category of perceived benefit identified by teachers in this study is that implementing mobile applications. addresses individual differences, referring to students' diverse academic levels. This finding was seldom addressed by previous studies and this indicates that implementing mobile applications. can be an appropriate solution to address the challenge of student diversity, in addition to the issue of a lack of motivation, located in the Jordani context (Said, 2016).

Regarding teachers' beliefs about their roles, the metaphor results depicted certain aspects of change that mainly took place in two categories shifting from subject matter expertise to didactical expertise, which is regarded as one of the most common beliefs reflecting constructivist views of learning for teaching Beijaard et al. (2000) after implementing mobile applications. implementation. This shift is aligned with the results of previous studies documenting the same direction of transformation through teachers' believed roles from subject focus to didactics priority when implementing innovative teaching strategies (Beijaard, Verloop, \& Vermunt, 2000; Dole, Bloom \& Kowalske, 2016; Liljedahl, 2008; Liljedahl et al., 2007). This direction of belief change is expected and aligned with the previous studies in higher levels of education that demonstrate that in order to successfully implement implementing mobile applications., it is essential for teachers to develop understanding of and belief in implementing mobile applications. which is embedded in constructivism and studentcentered approach to teaching (Dole, Bloom \& Kowalske, 2016; Kolmos, Du, Dahms, \& Qvist, 2008; Lee, Blackwell, Drake \& Moran, 2014; Pecore, 2012; Salvin-Baden, 2003).

Previous studies suggested that teachers' beliefs about teaching and learning, and their roles affected their decisions when planning and designing activities (Mihaela \& Alina-Oana, 2015; Pajares, 2003). Although implementing mobile applications. practice revealed a shift from lecture-centered to more student-centered methods, a gap was observed comparing their positive perception of implementing mobile applications. and perceived belief change with their actual implementation practices. Certain change was observed when comparing their lesson plans prior to and after three years of implementing mobile applications. implementation. These teachers included visibly more student 
interactive activities through team work, however, they revealed various ways of defining roles of learners and teachers in the implementing mobile applications. process and communicating with students. In particular, more than half of them displayed their tendency of control in defining the mathematical problems to be used in classroom, directing and guiding the classroom activities. This finding revealed that despite teachers' positive attitudes and desire to use new instructional strategies, the actual implementation can be more difficult and time-consuming (Tamim \& Grant, 2013). Comparing this to the results of previous studies on implementing mobile applications. n secondary (Jerzembek \& Murphy, 2013; Fletcher et al., 2000) and higher education (Hmelo-Silver \& Barrows, 2006; Norman \& Schmidt, 2000; Zhou et al., 2012), that encourage students to explore ill-structured problems from real life settings, the outcome of this study indicates that scaffolding and direct instruction may be more needed in primary education than higher levels. This also suggests that different types of problems and approaches to applying implementing mobile applications. in classrooms are needed for lower and upper grade of K12 education and higher education.

The discrepancy between teachers' perceived belief changes and their actual practices could be attributed to the challenges they defined, including teachers' insecurity and lack of confidence, difficulty in facilitating student collaboration, structural constraints, additional workload, and the lack of peer and school support. These issues became constraints that urged teachers to adjust their practices that are distant from their beliefs. These challenges are seemingly inconsistent with studies in higher levels of education, nevertheless, they may reflect different levels and attribute for different reasons. Previous studies also identified teachers' lack of confidence (Du \& Chaaban, 2019; Kolmos et al., 2008b, 2008a) and challenges of helping students to engage in team projects and problem-solving processes (Lee, Blackwell, Drake, \& Moran, 2014), which could be due to the initial experience of implementing mobile applications. regardless of educational levels. Nevertheless, it seems that teachers from primary education, in particular, in Jordan, may be more influenced by the institutional constraint regarding fulfilling curriculum standards and consequences of potential failure. This could be a feature of a top-down approach to change to implementing mobile applications., which, compared to the often-encouraged bottom-up approach to change in higher education (Kolmos, 2012; Moesby, 2004), can be more time-consuming for teachers to become true believers and change their practices accordingly.

Assessment remains an area with tremendous struggles in implementing mobile applications. at all educational levels in terms of reaching agreement on what to access, how to access and who should access, and whether the teachers have the skills to develop assessment tools aligning implementing mobile applications goals (Lee, Blackwell, Drake, \& Moran, 2014; Salvin-Baden, 2004). Nevertheless, in the given context of the study, teachers play no active roles in defining assessment, which limits not only their practice but also their belief of successful outcome of implementing mobile applications at all educational levels demands supports of institutional resources such as releasing teachers from other tasks (Mosby, 2004). Higher educational institutions may have more autonomy to change policies than schools who are obligated to follow governmental policies, which offers less flexibility regarding adjusting work hours and time schedule, and providing opportunities for teachers to collaborate (Chaaban \& Du, 2017). Furthermore, findings from the current study may also be related to the given context of Arab culture, that may influence teachers' beliefs and practices (Wu et al., 2011). For example, expressing options in front of others is an important skill for a network environment, however, female students in Middle Eastern culture may find it challenging because engaging in public discussion does not fit the traditional cultural ideology of femininity (Frambach et al., 2012). 


\section{CONCLUSION AND RECOMMENDATION}

Outcome of this study has a few implications. First, discrepancy between belief and practice of implementing mobile applications identified in this study suggests that appropriate and sufficient professional development activities are needed. In particular, providing teachers with opportunities to experience implementing mobile applications. as students would benefit their deep understanding and effective implementation. The MOE and schools in Jordan should further articulate policy goals and standards that facilitate student-centered approaches for teachers. System and institutional supports such as reducing teachers' workload, providing sufficient time for students' activities during implementing mobile applications sessions and for teachers' collaboration, and involving both students and teachers in defining assessment will benefit long term success of educational changes.

The current study several limitations. First, results of this study remain provisional due to the small number of participants and also because implementing mobile applications involves an ongoing change process. Second, the study focused on the teachers' perspectives, although it is an important angle to study educational change other perspectives such as learners' feedbacks and outcome are also essential. This indicates that follow up research on long term change of teachers' beliefs and practices, as well as perspectives from learners and management are needed. It is also crucial to gain more knowledge about students' learning outcome and performances in implementing mobile applications. in the lower grades of K12 education. In addition, comparative studies of teachers' perspectives with students' perceptions, performance, and learning outcomes in implementing mobile applications will provide additional knowledge about this change initiative in teaching and learning in K12.

\section{REFERENCES}

Abramovich, S. (2013). Computers in mathematics education: An introduction. Computers in the Schools, 30(1-2), 4-11.

Ahonen, E., Pyhältö, K., Pietarinen, J., \& Soini, T. (2014). Teachers' professional beliefs about their roles and the pupils' roles in the school. Teacher Development, 18(2), 177197.

Al Said, R. S., Du, X., ALKhatib, H. A. H., Romanowski, M. H., \& Barham, A. I. I. (2019). Math teachers' beliefs, practices, and belief change in implementing problem-based learning in Qatari primary governmental school.

Baki, A., Kosa, T., \& Guven, B. (2011). A comparative study of the effects of using dynamic geometry software and physical manipulatives on the spatial visualisation skills of pre-service mathematics teachers. British Journal of Educational Technology, 42(2), 291-310.

Beijaard, D., Verloop, N., \& Vermunt, J. D. (2000). Teachers' perceptions of professional identity: An exploratory study from a personal knowledge perspective. Teaching and Teacher Education, 16(7), 749-764.

Brinkmann, S., \& Kvale, S. (2005). Confronting the ethics of qualitative research. Journal of Constructivist Psychology, 18(2), 157-181.

Burridge, P., \& Carpenter, C. (2013). Expanding pedagogical horizons: A case study of teacher professional development. Australian Journal of Teacher Education, 38(9), 2. 
Chaamwe, N. (2010). Notice of Retraction: Integrating ICTs in the Teaching and Learning of Mathematics: An Overview. 2010 Second International Workshop on Education Technology and Computer Science, 1, 397-400.

Dias, L., \& Victor, A. (2017). Teaching and learning with mobile devices in the 21st century digital world: Benefits and challenges. European Journal of Multidisciplinary Studies, 2(5), 339344.

Dole, S., Bloom, L., \& Doss, K. K. (2017). Engaged learning: Impact of PBL and PjBL with elementary and middle grade students. Interdisciplinary Journal of Problem-Based Learning, 11(2), 9.

Du, X. (2012). A proposal of task-based PBL in Chinese teaching and learning. In Exploring task-based PBL in Chinese teaching and learning (pp. 36-61). Cambridge Scholars Press.

Du, X., \& Chaaban, Y. (2020). Teachers' Readiness for a Statewide Change to $\mathrm{PjBL}$ in Primary Education in Qatar. Interdisciplinary Journal of ProblemBased Learning, 14(1), n1.

Du, X., Su, L., \& Liu, J. (2013). Developing sustainability curricula using the PBL method in a Chinese context. Journal of Cleaner Production, 61, 80-88.

Fletcher, G. J., Simpson, J. A., \& Thomas, G. (2000). Ideals, perceptions, and evaluations in early relationship development. Journal of Personality and Social Psychology, 79(6), 933.

Frambach, J. M., Driessen, E. W., Chan, L.C., \& van der Vleuten, C. P. (2012). Rethinking the globalisation of problem-based learning: How culture challenges self-directed learning. Medical Education, 46(8), 738-747.

Fullan, M. (2014). Teacher development and educational change. Routledge.

Galligan, L., Loch, B., McDonald, C., \& Taylor, J. A. (2010). The use of Tablet and related technologies in mathematics teaching. Australian Senior Mathematics Journal, 24(1), $38-51$.

Grant, M. M., Tamim, S., Brown, D. B., Sweeney, J. P., Ferguson, F. K., \& Jones, L. B. (2015). Teaching and learning with mobile computing devices: Case study in K-12 classrooms. TechTrends, 59(4), 32-45.

Gürsul, F., \& Keser, H. (2009). The effects of online and face to face problem based learning environments in mathematics education on student's academic achievement. Procedia-Social and Behavioral Sciences, 1(1), 2817-2824.

Hmelo-Silver, C. E., \& Barrows, H. S. (2006). Goals and strategies of a problem-based learning facilitator. Interdisciplinary Journal of ProblemBased Learning, 1(1), 4.

Hohenwarter, M., \& Lavicza, Z. (2007). Mathematics teacher development with ICT: Towards an International GeoGebra Institute. Proceedings of the British Society for Research into Learning Mathematics, 27(3), 49-54.

Hollerbrands, K. F. (2007). The role of a dynamic software program for geometry in the strategies high school mathematics students employ. Journal for Research in Mathematics Education, 38(2), 164-192. 
Kazemi, F., \& Ghoraishi, M. (2012). Comparison of problem-based learning approach and traditional teaching on attitude, misconceptions and mathematics performance of University Students. Procedia-Social and Behavioral Sciences, 46, 38523856.

Kebritchi, M., Hirumi, A., \& Bai, H. (2010). The effects of modern mathematics computer games on mathematics achievement and class motivation. Computers \& Education, 55(2), 427443.

Kolmos, A., Du, X., Dahms, M.-L., \& Qvist, P. (2008a). Problem Based Master in Problem Based Learningin Engineering and Science at Aalborg University.

Kolmos, A., Du, X.-Y., Dahms, M., \& Qvist, P. (2008b). Staff development for change to problem based learning. International Journal of Engineering Education, 24(4), 772-782.

Korenova, L. (2012). The use of A digital environment for developing the creativity of mathematically gifted high school students. 12th International Congress on Mathematical Education, Seoul, Korea.

Korthagen, F. A. (2010). Situated learning theory and the pedagogy of teacher education: Towards an integrative view of teacher behavior and teacher learning. Teaching and Teacher Education, 26(1), 98-106.

Kvale, S., \& Brinkmann, S. (2009). Interviews: Learning the craft of qualitative research interviewing. sage.
Laius, A., Kask, K., \& Rannimäe, M. (2009). Comparing outcomes from two case studies on chemistry teachers' readiness to change. Chemistry Education Research and Practice, 10(2), 142-153.

Lakoff, G., \& Johnson, M. (2008). Metaphors we live by. University of Chicago press.

Lee, J. S., Blackwell, S., Drake, J., \& Moran, K. A. (2014). Taking a leap of faith: Redefining teaching and learning in higher education through projectbased learning. Interdisciplinary Journal of Problem-Based Learning, $8(2), 2$.

Leong, K. E. (2013). Impact of Geometer's Sketchpad on Students Achievement in Graph Functions. Leong, $K E$ (2013). Impact of Geometer's Sketchpad On Students Achievement In Graph Functions. Malaysian Online Journal of Educational Technology, 1(2), 19-33.

Li, Q. (2007). Student and teacher views about technology: A tale of two cities? Journal of Research on Technology in Education, 39(4), 377-397.

Li, Q., \& Ma, X. (2010). A meta-analysis of the effects of computer technology on school students' mathematics learning. Educational Psychology Review, 22(3), 215-243.

Liljedahl, P. (2008). Teachers' beliefs as teachers' knowledge. Symposium on the Occasion of the 100th Anniversary of ICMI, Rome. Retrieved August, 17, 2008.

Liljedahl, P., Rolka, K., \& Rösken, B. (2007). Belief change as conceptual change. European Research in Mathematics 
Education V. Proceedings of CERME5, 278-287.

Löfström, E., \& Poom-Valickis, K. (2013). Beliefs about teaching: Persistent or malleable? A longitudinal study of prospective student teachers' beliefs. Teaching and Teacher Education, 35, 104-113.

Mihaela, V., \& Alina-Oana, B. (2015). (When) teachers' pedagogical beliefs are changing? Procedia-Social and Behavioral Sciences, 180, 1001-1006.

Moesby, E. (2004). Reflections on making a change towards Project Oriented and Problem-Based Learning (POPBL). World Transactions on Engineering and Technology Education, 3(2), 269278.

Namey, E., Guest, G., Thairu, L., \& Johnson, L. (2008). Data reduction techniques for large qualitative data sets. Handbook for Team-Based Qualitative Research, 2(1), 137-161.

Norman, G. R., \& Schmidt, H. G. (2000). Effectiveness of problem-based learning curricula: Theory, practice and paper darts. Medical Education, 34(9), 721-728.

Pajares, F. (2003). Self-efficacy beliefs, motivation, and achievement in writing: A review of the literature. Reading \&Writing Quarterly, 19(2), 139-158.

Patton, M. Q. (2014). Qualitative evaluation and research methods: Integrating theory and practice. Sage Publications.

Said, Z. (2016). Science education reform in Qatar: Progress and challenges. Eurasia Journal of Mathematics,
Science and Technology Education, 12(8), 2253-2265.

Savin-Baden, M. (2003a). Disciplinary differences or modes of curriculum practice? Who promised to deliver what in problem-based learning? Biochemistry and Molecular Biology Education, 31(5), 338-343.

.. (2003b). Facilitating problem-based learning. McGraw-Hill Education (UK).

Schoenfeld, A. H. (2016). Learning to think mathematically: Problem solving, metacognition, and sense making in mathematics (Reprint). Journal of Education, 196(2), 1-38.

Sungur, S., \& Tekkaya, C. (2006). Effects of problem-based learning and traditional instruction on self-regulated learning. The Journal of Educational Research, 99(5), 307-320.

Talmy, S. (2010). Qualitative interviews in applied linguistics: From research instrument to social practice. Annual Review of Applied Linguistics, 30, 128.

Tamim, S. R., \& Grant, M. M. (2013). Definitions and uses: Case study of teachers implementing project-based learning. Interdisciplinary Journal of Problem-Based Learning, 7(2), 3.

Thomas, K., \& Muñoz, M. A. (2016). Hold the phone! High school students' perceptions of mobile phone integration in the classroom. American Secondary Education, 44(3), 19-37.

Törner, G. (2002). Mathematical beliefs-A search for a common ground: Some theoretical considerations on structuring beliefs, some research 
questions, and some phenomenological observations. In Beliefs: A hidden variable in mathematics education? (pp. 73-94). Springer.

Wu, H.-P., Palmer, D. K., \& Field, S. L. (2011). Understanding teachers' professional identity and beliefs in the Chinese heritage language school in the USA. Language, Culture and Curriculum, 24(1), 47-60.
Zhao, X., Wan, X., \& Okamoto, T. (2010). Adaptive content delivery in ubiquitous learning environment. 2010 6th IEEE International Conference on Wireless, Mobile, and Ubiquitous Technologies in Education, 19-26.

Zhou, C., Kolmos, A., \& Nielsen, J. F. D. (2012). A problem and project-based learning (PBL) approach to motivate group creativity in engineering education. International Journal of Engineering Education, 28(1), 3-16. 